\title{
Phytochemical Assays of Commercial Botanical Dietary Supplements
}

\author{
Robert Krochmal, Mary Hardy, Susan Bowerman, Qing-Yi Lu, H-J Wang, RM Elashoff \\ and David Heber
}

UCLA Center for Human Nutrition, UCLA, USA

The growing popularity of botanical dietary supplements (BDS) has been accompanied by concerns regarding the quality of commercial products. Health care providers, in particular, have an interest in knowing about product quality, in view of the issues related to herb-drug interactions and potential side effects. This study assessed whether commercial formulations of saw palmetto, kava kava, echinacea, ginseng and St. John's wort had consistent labeling and whether quantities of marker compounds agreed with the amounts stated on the label. We purchased six bottles each of two lots of supplements from nine manufacturers and analyzed the contents using established commercial methodologies at an independent laboratory. Product labels were found to vary in the information provided, such as serving recommendations and information about the herb itself (species, part of the plant, marker compound, etc.) With regard to marker compound content, little variability was observed between different lots of the same brand, while the content did vary widely between brands (e.g. total phenolic compounds in Echinacea ranged from 3.9-15.3 mg per serving; total ginsenosides in ginseng ranged from 5.3-18.2 mg per serving). Further, the amounts recommended for daily use also differed between brands, increasing the potential range of a consumer's daily dose. Echinacea and ginseng were the most variable, while St. John's wort and saw palmetto were the least variable. This study highlights some of the key issues in the botanical supplement market, including the importance of standardized manufacturing practices and reliable labeling information. In addition, health care providers should keep themselves informed regarding product quality in order to be able to appropriately advise patients utilizing both conventional and herbal medicines.

Keywords: botanical - quality - manufacturing practice

\section{Introduction}

Over the last 10 years, complementary and alternative (CAM) therapies have grown into a multibillion dollar industry in the United States (1-4). In particular, the use of botanical dietary supplements (BDS) has surged, with more than 60 million Americans now using herbal or other supplements, and spending over $\$ 600$ million annually on botanical products alone (5). This new era of popularity with BDS in the United States is accompanied by questions regarding the quality, consistency and safety of commercially available herbal products. Among the uncertainties associated with the use of BDS are variability in label information (6) and product composition (7).

For reprints and all correspondence: Robert Krochmal, UCLA Center for Human Nutrition, 900 Veteran Avenue, Los Angeles, CA 90095, USA.

Tel: (310) 206 1987; E-mail: rkrochmal@ mednet.ucla.edu
With the rise in the simultaneous use of both herbal and conventional modalities (8), health care providers, in particular, have a vital stake in knowing what their clients are consuming and in assessing the quality of these products. Such data would contribute to the safe use of herbs by ensuring consistency of dose of herbal actives. Health care providers who are currently hesitant to recommend or discuss BDS use with their patients (9-12) would likely be less reticent if they were confident about the product quality.

Recently, Garrard et al. (6) found wide-ranging label differences in the stated ingredients and recommended daily serving sizes across multiple brands for ten different herbs. However, this study did not attempt to correlate label claims with the actual contents. As a result, the question regarding the accuracy in the stated composition of the products remained unanswered. To date, few comparative analyses of the quality of

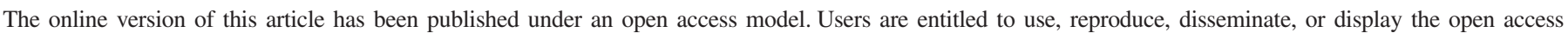

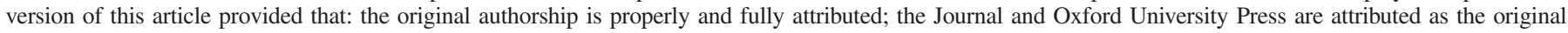

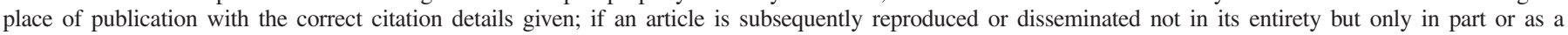
derivative work this must be clearly indicated. 
marketed herbal products exist, and of these, most come from large consumer organizations (13-14), not independent academic institutions (15). At our Center, we have previously tested nine brands of Chinese Red Yeast Rice, and it was found that these products varied greatly in their content of monacolin $\mathrm{K}$ and total monacolins (16). In the literature, studies on St. John's wort describe wide variability in marker compound content among the different commercial brands (17-19). An investigation of commercial ginseng products also found variability in the concentration of marker compounds, although the data did suggest that at least the US ginseng products are correctly labeled as to the plant genus (20). Other studies involving feverfew (21), garlic (22) and other herbs (23) also suggest inconsistencies among products with regard to the content of marker compounds.

In the current study, we examined five of the top selling (2) herbs in the United States-St. John's wort, ginseng, saw palmetto, kava kava and echinacea. The aim was to evaluate the quality and consistency of the available commercial products and to use this information to inform practitioners regarding the use of BDS. After documenting the label information, we analyzed the products for the presence or absence of toxic metal contaminants and for the presence and quantity of marker compound.

\section{Materials and Methods}

In order to sample the products most likely to be available to the average consumer, we purchased the products from nine manufacturers, found at chain pharmacies and retail stores, and through internet and mail order. All the products were nationally distributed at the time of the study and were chosen based upon their availability at the targeted outlets at the time of purchase. A total of twelve bottles of each herb (six bottles each of two different lot numbers) were purchased from all the identified manufacturers for which the herb was available. Phytochemical analysis was performed at an independent laboratory (Alpha Chemical and Biomedical Laboratories, Inc., Petaluma, CA) in order to replicate the resources available to commercial providers. The methodologies followed were those commonly used at the time of conducting this study, i.e., in late 1999. All samples were tested prior to the expiration dates listed on the bottles.

\section{Label Analysis}

For each supplement, information obtained from the labels and packaging were analyzed for the plant species, part of the plant utilized, method of preparation (e.g. dried herb, extract, etc.), type of marker compound, claimed amounts of marker compound and suggested daily serving size. Where necessary, the quality control departments of the companies were contacted in order to augment the information not available on the label.

\section{Content Analysis}

Once label information was recorded, unopened bottles were sent to the independent laboratory for analysis. Three pills from each bottle were analyzed and reported as pooled results. For each herb, a marker compound was identified and quantified by high-performance liquid chromatography (HPLC) in all the herbs except for saw palmetto, in which free fatty acids were measured by gas chromatography. Sigma reference standards were used in the content analysis.

\section{Echinacea}

The echinacea products were analyzed by HPLC, and the marker compounds were reported as total phenolic compounds, including echinacoside, cattaric acid, chlorogenic acid and cichoric acid. Samples were prepared by heating $0.1 \mathrm{~g}$ of ground plant material or extract in a $40 \mathrm{ml}$ vial with $20.0 \mathrm{ml}$ of methanol for $15 \mathrm{~min}$, sonicating and adding an additional 20 $\mathrm{ml}$ of water. Samples were filtered prior to HPLC analysis.

\section{Saw Palmetto}

Saw palmetto was analyzed for free fatty acids using gas chromatography with flame ionization detection (GC-FID). This procedure utilized derivatization of free fatty acids with BSTFA (99\%):TMCS (1\%) reagent. This reagent does not hydrolyze or transesterify fatty acids present as methyl, ethyl esters, triglycerides or wax esters that may be added to the formulations of saw palmetto.

\section{Ginseng}

Ginseng was analyzed by HPLC for seven of these compounds and reported as total ginsenosides. The ginsenosides were separated by reverse phase liquid chromatography on a C-18 column and detected with UV at $210 \mathrm{~nm}$. Quantification was carried out by the comparison of peak areas from the sample with those of the reference standards.

\section{St. John's Wort}

St. John's wort was measured for hypericin by HPLC analysis. Samples were prepared with a 90:10 MeOH:DMSO solvent and filtered through a 45-nm PTFE syringe filter. This sample was compared with hypericin standard and detected with UV at $590 \mathrm{~nm}$.

\section{Kava Kava}

Kava Kava was analyzed by HPLC and reported as total kavalactones, including methysticin, dihydromethysticin, kawain, dihydrokawain, yangonin and desmethoxyyangonin. An appropriate standard of d,1-Kawain was prepared with methanol and detection was performed at UV $220 \mathrm{~nm}$.

\section{Heavy Metals}

Heavy metals (lead, arsenic, cadmium and mercury) were analyzed by X-ray spectrophotometry and reported as percentages (by weight) in the test substance.

\section{Data Analysis}

Results for both lot numbers for each of the herbs were pooled and reported as average amounts of marker compound measured. 
For the products that made label claims of marker content, measured amounts were also reported as a percentage of the claimed amounts. Suggested daily serving sizes were calculated by multiplying the claimed amount of marker compound (where available) with the recommended intake per day. Actual daily serving sizes were calculated by multiplying the measured amounts of the marker compound with the recommended daily intake, assuming that consumers would correctly follow the instructions on the label. Suggested and actual daily serving sizes were then compared. Cases in which the product labels recommended a range of serving size (e.g. 1-3 caps), the results were reported as a range.

\section{Results}

\section{Products Obtained for Analysis}

For the products that were purchased over-the-counter, six bottles each of identical preparations from two different lots were obtained. For the supplements purchased via mail order, we were able to obtain six bottles each from two different lots; however, the preparations were not always consistent between lots. For example, in one instance, a supplier sent six bottles of one lot containing aerial parts of Echinacea purpurea and six bottles of another lot containing root of Echinacea purpurea and angustifolia. The same supplier sent six bottles of ginseng extract and six bottles of ginseng root.

\section{Label Information}

Product labels were found to vary in the information provided. In most cases, the manufacturers' quality control personnel were contacted and requested to verify the plant species, plant part and extraction procedure for the particular supplement by providing them with the lot numbers utilized in the study. Most manufacturers were able to provide the requested information, but some were not. Certain quality control personnel were difficult to contact; one was unable to locate records (they no longer manufactured the product at the time of contact) and another stated 'legal concerns' of providing this information over the phone. By and large, however, most manufacturers were very willing to be helpful in providing this information.

\section{Overall Analysis}

When the amount of marker compound was analyzed for individual samples within the same lot of a given brand, the content did not vary substantially. However, the measured amounts often varied from the stated amounts on the label, and some brands made no claims regarding the marker compound content at all for certain supplements. In general, variation between different lots of the same brand was relatively less than the variation between brands (Fig. 1). For certain herbs (saw palmetto, St. John's wort and kava kava), the plant species, part of the plant utilized and the type of preparation were consistent across brands, whereas other herbs (echinacea and ginseng) were more variable. All the products contained the marker compounds appropriate to the herb tested for, suggesting

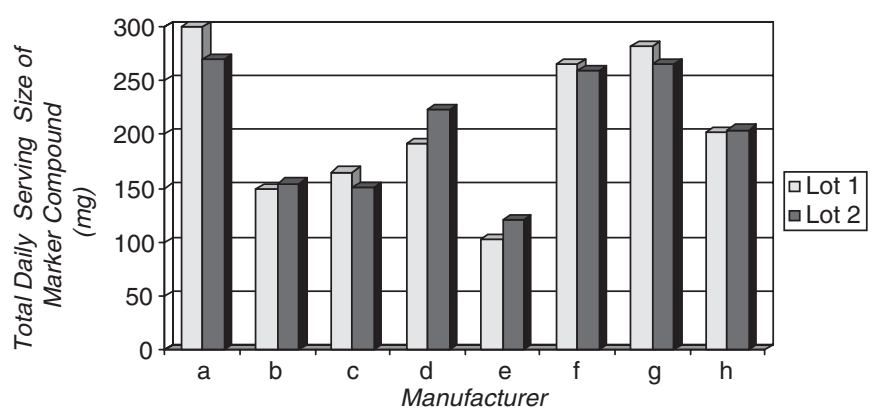

Figure 1. Comparison of Variability of Saw Palmetto Formulations Between Different Lots of the Same Brand and Between Brands.

at the very least that the products contained the correct herb. Finally, amounts of heavy metals, where detected, were below acceptable standards, in accordance with the California Proposition 65 (24).

\section{Echinacea}

For echinacea (Table 1), a total of ten different preparations were tested since brand 'b' sent two different preparations. Six of the ten preparations utilized Echinacea purpurea, one used purpurea and angustifolia, one used angustifolia and/or pallida and the species for two preparations were unavailable. Four of the ten products used both aerial parts and root, two used just aerial parts, two used just root and information on the remaining two products was unavailable.

Of all the samples tested, the echinacea (and ginseng; see below) products were the most variable. For those echinacea products that stated the amounts of the marker compound, two out of six $(33 \%)$ were within $\pm 10 \%$ of their claim. Four of the ten echinacea preparations made no claims regarding the amount of marker compound at all, and the type of marker compound itself was unavailable in six of the ten preparations. Among the others, no consistency was observed in the stated marker compound, whether it was echinacosides, phenolics or acylamides. Measured amounts of the marker compound for echinacea ranged from $78-173 \%$ of the stated amounts. Calculations for the actual daily dose of echinacea ranged between 7 and $137.7 \mathrm{mg}$ of echinacosides.

\section{Ginseng}

For ginseng (Table 2), a total of nine preparations were tested since one brand ('e') was unavailable, and one brand ('b') sent one lot of root and one lot of extract via mail order. Measured amounts ranged from $44-261 \%$ of the stated amounts. For those products that stated the amounts of the marker compound, one out of seven $(14 \%)$ were within $\pm 10 \%$ of their claim. Calculations for the actual daily dose of total ginsenosides ranged from 10.6-72.8 $\mathrm{mg}$ among the brands.

\section{St. John's Wort}

For St. John's wort (Table 3), ten products were tested. One product ('i') was unavailable and two products ('e' and ' $\mathrm{f}$ ') sent 
Table 1. Echinacea formulations

\begin{tabular}{|c|c|c|c|c|c|c|c|c|c|}
\hline Manufacturer & Species & Plant part & Preparation & Standardization & $\begin{array}{l}\text { Stated amount } \\
\text { of marker }(\mathrm{mg})\end{array}$ & $\begin{array}{l}\text { Measured amount } \\
\text { marker (mg) (average } \\
\text { of two lots) }\end{array}$ & $\begin{array}{l}\text { Percent of } \\
\text { label claim }\end{array}$ & $\begin{array}{l}\text { Suggested } \\
\text { servings } \\
\text { per day }\end{array}$ & $\begin{array}{l}\text { Total daily dose } \\
\text { of marker compound } \\
\text { (mg) }\end{array}$ \\
\hline$a$ & $\begin{array}{l}\text { Echinacea } \\
\text { purpurea }\end{array}$ & Herb and root & Extract & TLC $^{1}$ and FTIR $^{2}$ & - & $5.7 \pm 2.0$ & - & 6 & 34.2 \\
\hline$b(1)^{*}$ & $\begin{array}{l}\text { Echinacea } \\
\text { purpurea }\end{array}$ & Herb & Powder & N/A & 10 & $15.3 \pm 0.4$ & $153 \pm 4 \%$ & $3-9$ & $45.9-137.7$ \\
\hline$b(2)^{*}$ & $\begin{array}{l}\text { Echinacea } \\
\text { purpurea and } \\
\text { Echinacea } \\
\text { angustifolia }\end{array}$ & Herb and root & $\begin{array}{l}\text { Powder with } \\
\text { extract }\end{array}$ & Echinacoside & - & $9.6 \pm 0.7$ & - & 2 & 19.2 \\
\hline$c$ & N/A & N/A & N/A & N/A & 10 & $13.9 \pm 0.2$ & $139 \pm 2 \%$ & $1-4$ & $13.85-55.4$ \\
\hline$d$ & $\begin{array}{l}\text { Echinacea } \\
\text { purpurea }\end{array}$ & $\begin{array}{l}\text { Whole plant } \\
\text { and root }\end{array}$ & Extract & $4 \%$ phenolics & 5 & $5.4 \pm 0.2$ & $107 \pm 5 \%$ & 2 & 10.8 \\
\hline$e$ & $\begin{array}{l}\text { Echinacea } \\
\text { purpurea }\end{array}$ & Aerial & Powder & N/A & - & $12.6 \pm 0.2$ & - & $6-9$ & $75.6-113.4$ \\
\hline$f$ & $\begin{array}{l}\text { Echinacea } \\
\text { purpurea }\end{array}$ & Root & Extract & $\begin{array}{l}\text { Acylamides } \\
>0.3 \%\end{array}$ & - & $3.5 \pm 0.4$ & - & 2 & 7 \\
\hline$g$ & $\begin{array}{l}\text { Echinacea } \\
\text { purpurea }\end{array}$ & $\begin{array}{l}\text { Whole plant } \\
\text { and root }\end{array}$ & Extract & $4 \%$ phenolics & 5 & $5.2 \pm 0.7$ & $104 \pm 14 \%$ & 2 & 10.4 \\
\hline$h$ & N/A & N/A & N/A & N/A & 3 & $5.2 \pm 0.2$ & $173 \pm 7 \%$ & 2 & 10.4 \\
\hline$i$ & $\begin{array}{l}\text { Echinacea } \\
\text { angustifolia } \\
\text { and/or pallida }\end{array}$ & Root & Powder & N/A & 5 & $3.9 \pm 0.3$ & $78 \pm 7 \%$ & 2 & 7.8 \\
\hline
\end{tabular}

${ }^{1}$ Thin Layer Chromatography.

${ }^{2}$ Fourier Transform Infrared Spectroscopy.

*Reported as two separate products since different preparations were sent; N/A = information not available. 
Table 2. Saw palmetto formulations

\begin{tabular}{|c|c|c|c|c|c|c|c|c|c|}
\hline Manufacturer & Species & Plant part & Preparation & Standardization & $\begin{array}{l}\text { Stated amount } \\
\text { of marker }(\mathrm{mg})\end{array}$ & $\begin{array}{l}\text { Measured amount } \\
\text { marker (mg) (average } \\
\text { of two lots) }\end{array}$ & $\begin{array}{l}\text { Percent of } \\
\text { label claim }\end{array}$ & $\begin{array}{l}\text { Suggested } \\
\text { servings } \\
\text { per day }\end{array}$ & $\begin{array}{l}\text { Total daily dose } \\
\text { of marker compound } \\
(\mathrm{mg})\end{array}$ \\
\hline$a$ & Serenoa repens & Fruit & Extract & Match 'standard' & - & $45.1 \pm 0.9$ & - & 6 & 270.6 \\
\hline$b$ & Serenoa serrulata & Fruit & Extract & $75-85 \%$ fatty acids & - & $75.0 \pm 1.4$ & - & 2 & 150 \\
\hline$c$ & N/A & N/A & N/A & N/A & - & $52.4 \pm 2.3$ & - & $2-4$ & $104.8-209.6$ \\
\hline$d$ & Serenoa repens & Fruit & Extract & $80 \%$ fatty acids & 128 & $103.8 \pm 8.2$ & $81 \pm 6 \%$ & 2 & 207.6 \\
\hline$e$ & Serenoa repens & Fruit & Extract & $45 \%$ sterols & 36 & $27.8 \pm 2.5$ & $77 \pm 7 \%$ & 4 & 111.2 \\
\hline$f$ & Serenoa repens & Fruit & Extract & Total free fatty acids $35-45 \%$ & $136-152^{\#}$ & $133.2 \pm 1.4$ & $93 \pm 1 \%$ & 2 & 266.4 \\
\hline$g$ & Serenoa repens & Fruit & Extract & $80 \%$ fatty acids & 64 & $68.1 \pm 2.4$ & $106 \pm 4 \%$ & 4 & 272.4 \\
\hline$h$ & N/A & N/A & N/A & N/A & 128 & $101.6 \pm 0.7$ & $79 \pm 1 \%$ & 2 & 203.2 \\
\hline
\end{tabular}

*Reported as two separate products since lots were different preparations; "use 144 for comparison; N/A = information not available.

Table 3. Ginseng formulations

\begin{tabular}{|c|c|c|c|c|c|c|c|c|c|}
\hline Manufacturer & Species & Plant part & Preparation & Standardization & $\begin{array}{l}\text { Stated amount } \\
\text { of marker }(\mathrm{mg})\end{array}$ & $\begin{array}{l}\text { Measured amount } \\
\text { marker (mg) (average } \\
\text { of two lots) }\end{array}$ & $\begin{array}{l}\text { Percent of } \\
\text { label claim }\end{array}$ & $\begin{array}{l}\text { Suggested } \\
\text { servings } \\
\text { per day }\end{array}$ & $\begin{array}{l}\text { Total daily dose } \\
\text { of marker compound } \\
\text { (mg) }\end{array}$ \\
\hline$a$ & Panax ginseng & Root & Powder & $12 \mathrm{mg}$ ginsenosides & 12 & $5.3 \pm 0.2$ & $44 \pm 2 \%$ & 2 & 10.6 \\
\hline$b(\operatorname{lot} 1)^{*}$ & Panax ginseng & Root & N/A & N/A & 8.0 & $9.0 \pm 1.5$ & $112 \pm 19 \%$ & 4 & 36.0 \\
\hline$b(\operatorname{lot} 2)^{*}$ & Panax ginseng & Root & Softgel & $7 \%$ ginsenosides & 10.0 & $17.5 \pm 0.13$ & $175 \pm 1 \%$ & 2 & 35.0 \\
\hline$c$ & N/A & N/A & N/A & N/A & 7.0 & $18.2 \pm 0.4$ & $261 \pm 6 \%$ & $1-4$ & $18.2-72.8$ \\
\hline$d$ & Panax ginseng & Root & Extract & $7 \%(7 \mathrm{mg}$ ) ginsenosides & 7.0 & $7.4 \pm 0.6$ & $106 \pm 8 \%$ & 3 & 22.2 \\
\hline$f$ & Panax ginseng & Root & Extract & $5 \%$ ginsenosides & $\geq 5.0$ & $7.3 \pm 1.0$ & - & 2 & 14.6 \\
\hline$g$ & Panax ginseng & Root & Extract & $7 \%(7 \mathrm{mg}$ ) ginsenosides & 7.0 & $8.2 \pm 0.3$ & $117 \pm 4 \%$ & 3 & 24.6 \\
\hline$h$ & N/A & N/A & N/A & N/A & 7.0 & $8.0 \pm 0.5$ & $114 \pm 6 \%$ & 2 & 16.0 \\
\hline$i$ & N/A & N/A & N/A & N/A & - & $11.1 \pm 1.4$ & - & 2 & 22.2 \\
\hline
\end{tabular}

*Reported as two separate products since lots were different preparations; N/A = information not available. 


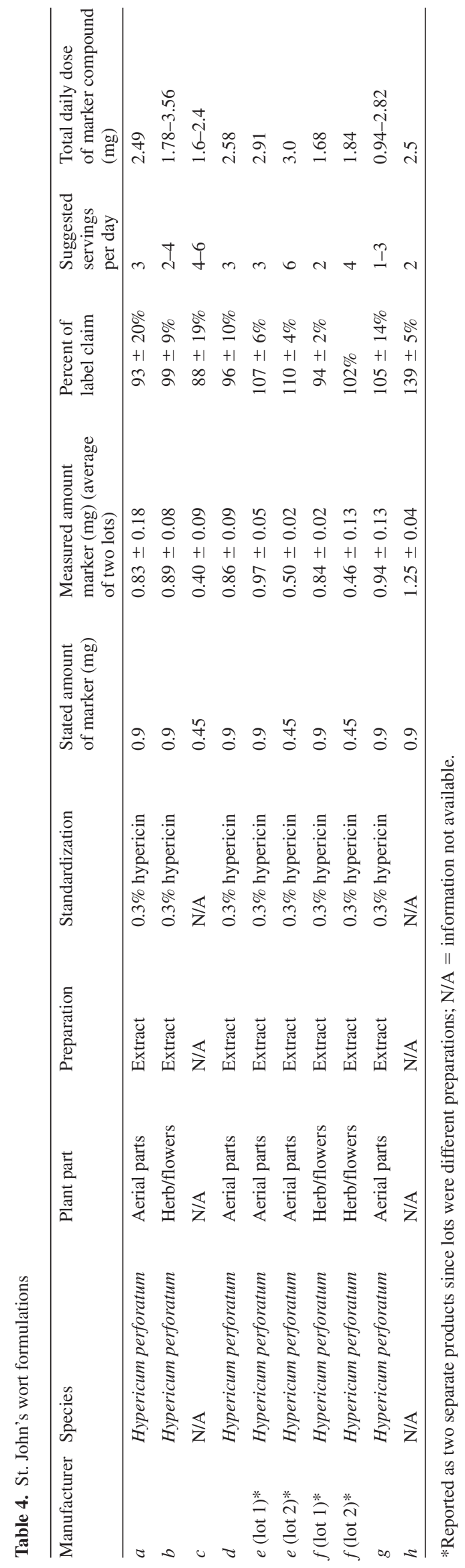

two different preparations. Measured amounts of hypericin were mostly consistent among brands, ranging from $88-110 \%$ of the stated amounts. One outlier contained $139 \%$ of the stated amount. All the ten products stated the amounts of marker compound, and eight of these $(80 \%)$ were within $\pm 10 \%$ of their claim. Stated amounts of the marker compound were either $0.45 \mathrm{mg}$ or $0.9 \mathrm{mg}$ per capsule, and all the brands used the same type of preparation. Calculations for the actual daily doses ranged from $0.9-3.56 \mathrm{mg}$ hypericin per day.

\section{Saw Palmetto}

Eight saw palmetto products (Table 4) were tested. Product 'i' was unavailable. Marker compounds ranged from $77-106 \%$ of the stated amounts. Three of the eight preparations made no claims regarding the marker compounds. Of the remaining five, two $(40 \%)$ were within $\pm 10 \%$ of their claim. Calculations of the actual daily doses ranged from 111.2-272.4 mg/day among the brands investigated.

\section{Kava Kava}

Eight kava products (Table 5) were tested. Products 'h' and 'i' were unavailable and product ' $b$ ' sent two different preparations. Total kavalactones ranged from $42-133 \%$ of the stated amounts. The stated amounts ranged from $10-70 \mathrm{mg}$ of kavalactones per tablet, and one of the eight preparations made no claim regarding the marker compound. Of the remaining seven, five $(71 \%)$ were within $\pm 10 \%$ of their claim. Actual calculated daily doses were between 41.7 and $220 \mathrm{mg}$ of kavalactones among the commercial brands.

\section{Discussion}

Consistent with previous studies (6), the current study found that product labels of BDS vary in the information provided. Particularly, for echinacea and ginseng, the labels often varied with regard to the plant species, part of the plant utilized, type of preparation, type of marker compound, standardization of marker compound, claimed amounts of marker compound and the recommended serving size. While the content tended not to vary either within the same lot or across different lots of a given brand, considerable differences between stated and actual amounts of marker compound were found in most brands. In addition, large differences were observed in the marker compound content among brands. This problem, coupled with the inconsistency in the recommended serving sizes, led to even greater variability in the potential daily ingestion of presumed active constituents.

St. John's wort and saw palmetto were the two herbs with the least variability among brands for the stated and measured amounts of marker compound as well as for the recommended serving sizes. It is notable that three major systematic reviews exist for both saw palmetto (25-27) and St. John's wort (28-30) and that standardized and consistent products have been used in these clinical trials. This consistency appears to be reflected in the relative uniformity of the commercially available products 


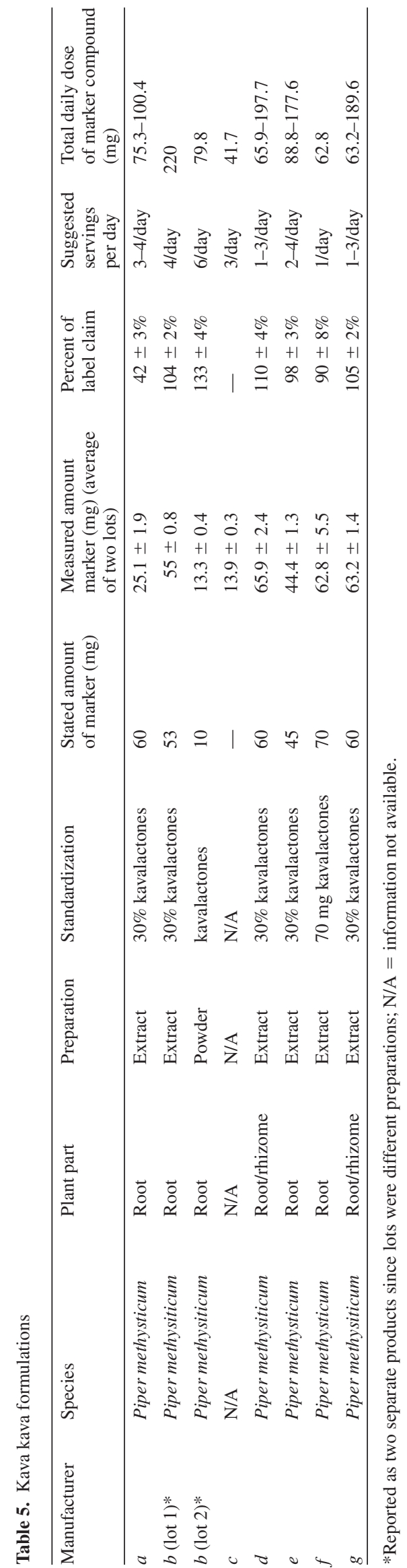

for these herbs. Although there are existing reviews for both echinacea and ginseng, there was no similar consensus in the clinical trials, and the products utilized varied for plant species, part of the plant and the type of preparation $(31,32)$. Given this difference, it is perhaps not surprising that the echinacea and ginseng reviews tend to report mixed results, whereas for saw palmetto and St. John's wort, results are generally positive. The prevalence of standardized formulations of St. John's wort and saw palmetto in randomized controlled trials therefore suggests a relationship between the quality of commercial products and the quality of evidence-based research on these products. It would follow that improvement in the scientific database on herbal efficacy and safety would be facilitated by improving the product quality and consistency.

A fundamental limitation of this study, and the state of the art in the science of botanical medicine in general, is that botanical marker compounds are not necessarily the biologically active ingredients (33). Even in the case of St. John's wort, for which the marker compound-hypericin—is well characterized, it is possible that another component-hyperforin-may be more active (34-36). Therefore, currently, the purpose of marker compounds is limited to their action as surrogates to ensure the reproducibility and quality of the preparatory process. While this study does highlight the inconsistencies among the products, they may not necessarily correlate with differences in the clinical activity.

In addition, consensus in the dietary supplement industry on the methodology for quantifying phytochemical markers is not complete. Therefore, our study used commonly accepted methods in commercial use available at that time. Presumably, the state of the art has advanced since this time, and it is possible that the products would be better characterized and validated with evolving methodologies. In addition, since the time of the study, the FDA has proposed new labeling requirements $(37,38)$ as well as manufacturing standards (38) (current good manufacturing practices-CGMPs) in order to ensure that BDS are manufactured consistently to 'identify purity, quality, strength and composition'. Therefore, as new methodological techniques are developed and published, some of the problems uncovered by this study will be eliminated. In addition, if the new FDA rules for CGMPs are approved and implemented, further quality improvements are likely to follow. Future investigations could assess the effect of evolving scientific and regulatory standards on improving product quality.

Given the growing concern regarding the potential for herbdrug interactions (39) as well as the adverse effects reported with some herbs (40), the current study does have implications for clinical practice. We suggest that when physicians determine that their patients are using BDS, they should ask them to bring in the bottles, along with their regular medicines. Health care providers can help their patients make informed purchasing choices, advising them to choose products most likely to be of high quality. While this study highlights the fact that label information may not always be complete or reliable, one should at least get into the habit of looking for the presence of the following: documentation of the exact amount of marker 
compound, botanical name of the herb, recommended serving size in milligrams, batch or lot number, expiration date and the name/address of the manufacturer. Finally, the presence of a Dietary Supplement Verification Certificate from the US Pharmacopeia, or other related groups, indicates a manufacturer's compliance with a quality validation program (41).

Once a product is chosen, it is important to note that switching brands during a course of treatment may affect the amount of presumed active constituents and therefore, the efficacy and safety. Given the brand-to-brand variability highlighted by this study, once a patient achieves a desired outcome with a BDS, it is inadvisable to change the serving size or brand. Following is a summary of the recommendations to health care providers discussing herbal supplement use with their patients.

\section{Recommendations to Physicians Guiding Patients in Herbal Supplement Use}

1. Ask your patients about herb use.

2. Ask patients to bring the bottles of the supplement with them during clinic visit.

3. Where possible, select products used in randomized, controlled trials.

4. Review efficacy/safety data with established resources (e.g. National Library of Medicine).

5. Recognize that switching brands may alter efficacy or side effects.

6. Note potential side effects or changes in efficacy in a chart.

7. If change in efficacy is reported, assess BDS label for change in source material.

8. When possible, check available resources on quality (e.g. ConsumerLab).

In the near future, the development of a more sophisticated knowledge base for botanical supplements will be accompanied by a rising demand for standardized manufacturing practices and quality control methods, reliable labeling information and knowledgeable health care providers able to advise patients utilizing both conventional and herbal modalities. It is critical that industry, government and academia work together to achieve further progress in assuring consumer access to high quality, safe dietary supplements. Such trends will further enable safe clinical practice and the testing of botanical supplements to proceed with confidence, thus contributing to the growing evidence base regarding their function and leading to more reliable commercial products with well-characterized safety and efficacy profiles.

\section{Acknowledgments}

This work was supported by the NIH Grant P50 AT00151 to the Center for Dietary Supplement Research: Botanicals at UCLA.

\section{References}

1. De Smet PA. Herbal remedies. N Engl J Med 2002;347:2046-56.

2. Eisenberg DM, et al. Trends in alternative medicine use in the United States, 1990-1997: results of a follow-up national survey. JAMA 1998;280:1569-75.
3. Ernst E, White A. The BBC survey of complementary medicine use in the UK. Complement Ther Med 2000;8:32-6.

4. Kessler RC, et al. Long-term trends in the use of complementary and alternative medical therapies in the United States. Ann Intern Med 2001;135:262-8.

5. Brevoort P. The booming US botanical market: a new overview. Herbalgram 1998;44:33-48.

6. Garrard J, et al. Variations in product choices of frequently purchased herbs: caveat emptor. Arch Intern Med 2003;163:2290-5.

7. Barnes J. Quality, efficacy and safety of complementary medicines: fashions, facts and the future. Part I. Regulation and quality. $\mathrm{Br} \mathrm{J}$ Clin Pharmacol 2003;55:226-33.

8. Fong HH. Integration of herbal medicine into modern medical practices: issues and prospects. Integr Cancer Ther 2002;1:287-93.

9. Corbin Winslow L, Shapiro H. Physicians want education about complementary and alternative medicine to enhance communication with their patients. Arch Intern Med 2002;162:1176-81.

10. Eisenberg DM. Advising patients who seek alternative medical therapies. Ann Intern Med 1997;127:61-9.

11. Sleath B, et al. Ethnicity and physician-older patient communication about alternative therapies. J Altern Complement Med 2001;7:329-35.

12. Smith M, Boon HS. Counseling cancer patients about herbal medicine. Patient Educ Couns 1999;38:109-20.

13. Herbal Roulette. Consumer Reports, November 1995;16:698-705.

14. The ConsumerLab Seal.

15. Tyler V. The quality of herbal products in the United States today. Healthnotes 1999;6.3:178-81.

16. Heber D, et al. An analysis of nine proprietary Chinese red yeast rice dietary supplements: implications of variability in chemical profile and contents. J Altern Complement Med 2001;7:133-9.

17. Ganzera M, Zhao J, Khan IA. Hypericum perforatum-chemical profiling and quantitative results of St. John's Wort products by an improved high-performance liquid chromatography method. J Pharm Sci 2002; 91:623-30.

18. Wurglics M, et al. Batch-to-batch reproducibility of St. John's wort preparations. Pharmacopsychiatry 2001;34 Suppl 1:S152-6.

19. de los Reyes GC, Koda RT. Determining hyperforin and hypericin content in eight brands of St. John's wort. Am J Health Syst Pharm 2002;59:545-7.

20. Harkey MR, et al. Variability in commercial ginseng products: an analysis of 25 preparations. Am J Clin Nutr 2001;73:1101-6.

21. Heptinstall S, et al. Parthenolide content and bioactivity of feverfew (Tanacetum parthenium (L.) Schultz-Bip.). Estimation of commercial and authenticated feverfew products. J Pharm Pharmacol 1992;44:391-5.

22. Krest I, Keusgen M. Quality of herbal remedies from Allium sativum: differences between alliinase from garlic powder and fresh garlic. Planta Med 1999;65:139-43.

23. Shardt D, Liebman B. Powder wise ... pill foolish. Nutrition Action Healthletter 1995;22:4-5.

24. California Proposition 65: Safe Drinking Water and Toxic Enforcement Act of 1986, O.E.H.H.A. (OEHHA), www.oehha.ca.gov/prop65.html.

25 . Wilt TJ, et al. Saw palmetto extracts for treatment of benign prostatic hyperplasia: a systematic review. JAMA 1998;280:1604-9.

26. Gerber GS. Saw palmetto for the treatment of men with lower urinary tract symptoms. J Urol 2000;163:1408-12.

27. Wilt T, Ishani A, Mac Donald R. Serenoa repens for benign prostatic hyperplasia. Cochrane Database Syst Rev 2002;3:CD001423.

28. Whiskey E, Werneke U, Taylor D. A systematic review and meta-analysis of Hypericum perforatum in depression: a comprehensive clinical review. Int Clin Psychopharmacol 2001;16:239-52.

29. Gaster B, Holroyd J. St John's wort for depression: a systematic review. Arch Intern Med 2000;160:152-6.

30. Linde K, et al. St John's wort for depression-an overview and metaanalysis of randomised clinical trials. BMJ 1996;313:253-8.

31. Melchart D, et al. Echinacea for preventing and treating the common cold. Cochrane Database Syst Rev 2000;CD000530.

32. Vogler BK, Pittler MH, Ernst E. The efficacy of ginseng. A systematic review of randomised clinical trials. Eur J Clin Pharmacol 1999;55:567-75.

33. Schulz V, Hansel R, Tyler V. Rational phytotherapy: a physician's guide to herbal medicine. Fourth ed. 2000; Berlin: Springer.

34. Chatterjee SS, et al. Hyperforin as a possible antidepressant component of hypericum extracts. Life Sci 1998;63:499-510.

35. Chatterjee SS, et al. Antidepressant activity of hypericum perforatum and hyperforin: the neglected possibility. Pharmacopsychiatry 1998;31 Suppl $1: 7-15$. 
36. Laakmann G, et al. St. John's wort in mild to moderate depression: the relevance of hyperforin for the clinical efficacy. Pharmacopsychiatry 1998;31 Suppl 1:54-9.

37. US Food and Drug Administration, Guidance for Industry Statement of Identity, Nutrition Labeling, and Ingredient Labeling of Dietary Supplements: Small Entity Compliance Guide. January 4, 1999.

38. FDA Proposes Labeling and Manufacturing Standards For All Dietary Supplements. March 7, 2003, U.S. Food and Drug Administration.
39. Fugh-Berman A. Herb-drug interactions. Lancet 2000;355:134-8.

40. Ernst E, Pittler MH. Risks associated with herbal medicinal products. Wien Med Wochenschr 2002;152:183-9.

41. U.S. Pharmacopeia Dietary Supplement Verification Program, http://www.uspverified.org/.

Received May 6, 2004; accepted August 20, 2004 


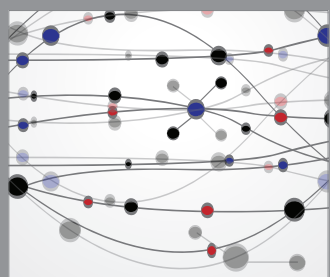

The Scientific World Journal
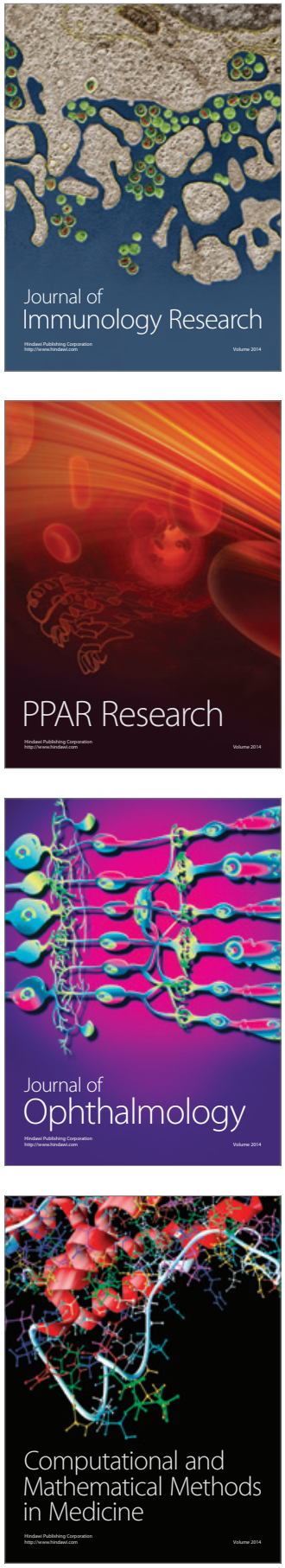

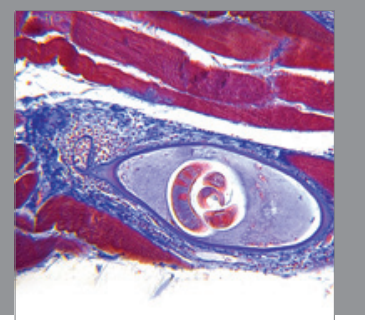

Gastroenterology

Research and Practice
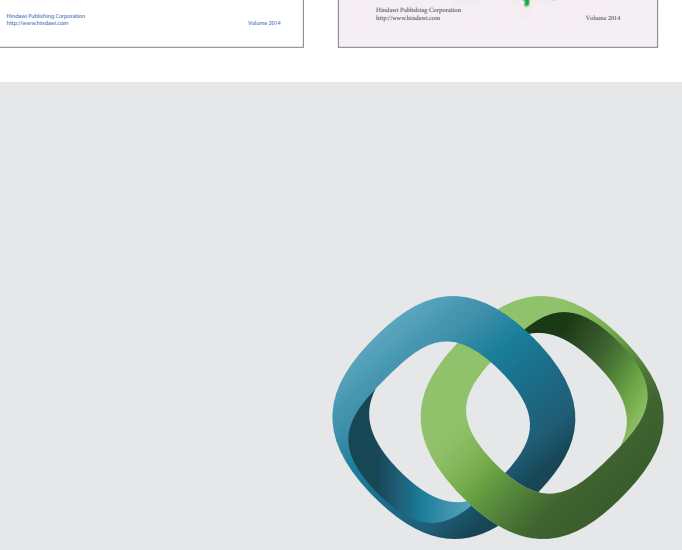

\section{Hindawi}

Submit your manuscripts at

http://www.hindawi.com
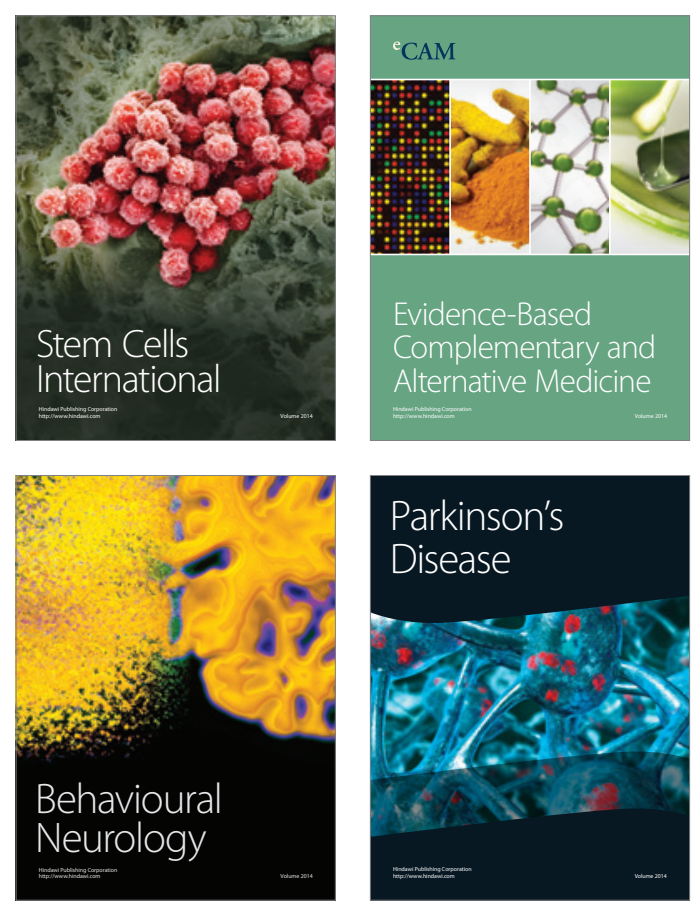

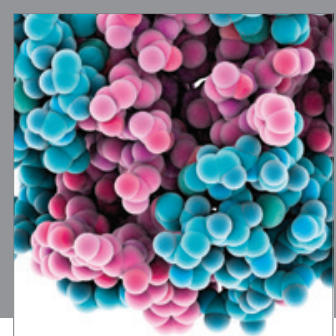

Journal of
Diabetes Research

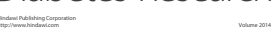

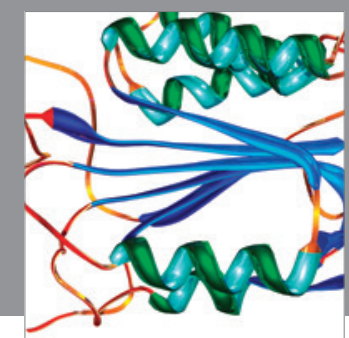

Disease Markers
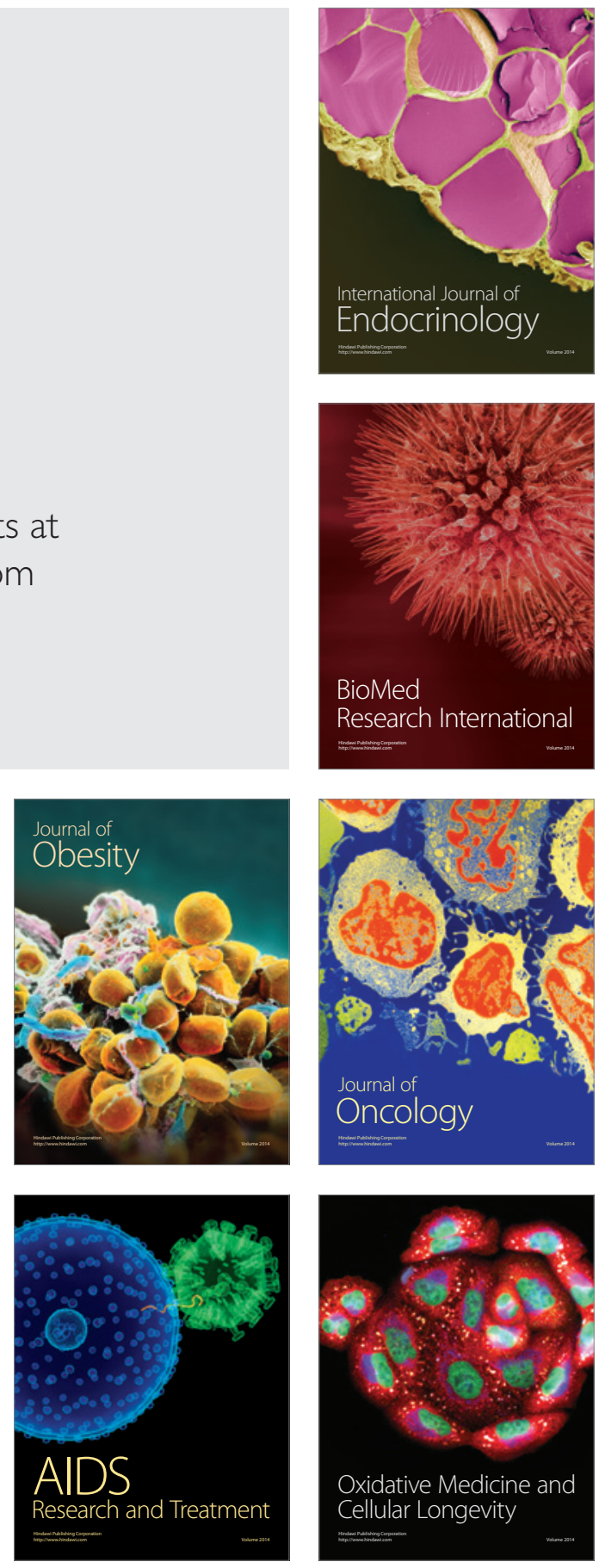